\title{
PLANKTON AND MACROINVERTEBRATE COMMUNITY COMPOSITION IN THE PELAGIC AND NON-VEGETATED LITTORAL DRAWDOWN ZONES OF A SHALLOW RESERVOIR, MANJIRENJI, ZIMBABWE
}

\author{
UTETE, B. ${ }^{1 *}-$ ZENDA, ${ }^{1}{ }^{1}-$ MBAUYA, W. A. ${ }^{1}-$ TSAMBA, J. $^{2}$ \\ ${ }^{1}$ Chinhoyi University of Technology, Department of Wildlife Ecology and Conservation P. Bag \\ 7724, Chinhoyi, Zimbabwe \\ ${ }^{2}$ University of Zimbabwe, Biological Sciences Department, P.O Box MP 167, Mt Pleasant, \\ Harare, Zimbabwe \\ *Corresponding author \\ e-mail:mkaiyo@gmail.com
}

(Received $21^{\text {st }}$ Oct 2016; accepted $28^{\text {th }}$ Jan 2017)

\begin{abstract}
We examined the influence of physicochemical variables on zooplankton, phytoplankton and macroinvertebrate community composition in a shallow dam, Manjirenji in Zimbabwe. And further explored the relations between selected water parameters on chlorophyll $a$ production as a proxy for phytoplankton biomass in the non-vegetated littoral drawdown zone in comparison to the pelagic zone. We observed high similarity overlaps between some water parameters, and a uniform dominance pattern of zooplankton comprising of rotifers > copepods > cladocera in littoral and pelagic sites, though the dominance order for phytoplankton varied significantly between lake zones. Pollution sensitive macroinvertebrate families dominated in the non-littoral vegetated drawdown zone. Physicochemical variables account for low plankton (50.37\%) and macroinvertebrates (59.59\%) ecogeography suggesting the influence of latent (unexplored) environmental and biotic factors on plankton and macroinvertebrate community composition in this lake. There was no significant predictor factor among Secchi depth, total nitrogen, and total phosphorus towards chlorophyll $a$ production in the Dam. Non-vegetation in littoral drawdown zones of the shallow turbid lake reduce habitat complexity conferring functional and structural similarity with the pelagic zone. There is a need to comprehend transitional nutrient and water hydrodynamics and their effects on aquatic biodiversity in shallow lakes.
\end{abstract}

Keywords: eulittoral zone; lake level fluctuation; alternative equilibria; ecosystem; fauna; assembly

\section{Introduction}

Shallow tropical lakes which are located in arid areas have extensive periods of low water levels intertwined with increased levels in the rain season (Antenucci et al., 2000). Natural water level fluctuations have associated effects on the water quality and resident aquatic communities (Wantzen et al., 2008), besides constantly shifting the drawdown zone. Though the effects of natural water level fluctuations on water quality and aquatic organisms are magnified if the dams have other non- seasonal water withdrawing activities present (Abrahams, 2008). Water level fluctuations serve to promote high species diversity in littoral zones of shallow lakes and for doubling the productivity of these lakes thus projecting fish densities in water bodies (Antenucci et al., 2003; Kolding and van Zwieten, 2012).

In shallow turbid lakes, spatial isolation, stochastic nutrient stoichiometry and water level fluctuations due to the constant shifting of the ecotone up and down the shoreline affects aquatic biodiversity (Wang et al., 2011; Kolding and van Zwieten, 2012). For this exploratory study, we examined the effects of physicochemical variables on the 
community composition of phytoplankton, zooplankton and macroinvertebrates in different zones of a shallow lake, Manjirenji in Zimbabwe, which is prone to extreme water level fluctuations. This shallow lake is unique as it has a non-vegetated shoreline (Utete and Tsamba, 2016). Regardless, we assumed that there were two alternative stable states in this shallow lake, largely adopting the alternative stable equilibria states framework by Scheffer et al. (1993). The relatively deeper pelagic zone acts as the first equilibrium state which predominates at low nutrient concentrations, and is characterised by abundant macrophytes and clear water. This state is stabilised by high zooplankton grazing rates, low planktivorous and benthivorous fish abundances and high piscivorous fish abundances, and thus a low macroinvertebrate abundance (Scheffer et al., 1993). And we assumed the second state, which is characterised by abundant phytoplankton and turbid water at relatively high nutrient concentrations to be prevalent in the littoral zone. This turbid state is stabilised by light limitation due to algal blooms and has high macroinvertebrate densities. We also assumed that at intermediate (similar) nutrient levels, both alternative stable states can occur within a shallow lake. Scheffer et al. (1993) considers that within a given background of biotic conditions, abiotic interactions may strongly influence both function and community structure at different trophic levels, including the zooplankton. Thus in this study we hypothesised that: shallow lakes with non-vegetated shorelines, show no demarcation or dissimilarity for plankton and macroinvertebrate community composition, and physicochemical variables between the open deeper pelagic and shallow littoral sites. Conversely, we explored the suggestion that a continuum in shallow lakes and nonsignificant spatial isolation confers similarity in nutrient stoichiometry, thus, we envisage similarities in plankton and macroinvertebrate community composition (Quiros, 2003).

Although most research on plankton and macroinvertebrates has focused on river reservoirs (transition from river to lake/reservoir) (Grzybkowska et al., 1990), other reservoir studies have been limited to pre- and post-impoundment surveys or have been done on systems that have irregular drawdown patterns or low winter water levels that subject the benthos to freezing (Kolding and van Zwieten, 2012). Few, or sparse studies have been conducted in shallow lakes with non-vegetated shorelines to explore the effect of stochasticity of nutrient stoichiometry on plankton and macroinvertebrates assemblages (Baldwin et al., 2008). The objective of this study was to investigate the influence of physicochemical variables and abundance on phytoplankton, zooplankton and benthic macroinvertebrates community composition in the non-vegetated littoral drawdown zone relative to the pelagic zone of a turbid shallow dam, Manjirenji in Zimbabwe, with multiple designated uses

\section{Materials and methods}

We carried out this study in Manjirenji Dam located in Zimbabwe, constructed from 1964-67 with the primary aim of irrigating sugar cane estates in Mkwasine and Triangle in Zimbabwe (ZINWA, 2014). The lake's hydrological history and morphometry is shown in Table 1. The Dam, a relatively shallow reservoir located in the located in the arid south eastern part of Zimbabwe is subject to wide water level fluctuations reaching a drastic $12.6 \%$ or 4.66 metres from an average of 24.2 metres in November 2012, 18.9\% in September 2013 and increasing to just below 40\% in January 2014 (ZINWA, 2014). Though the main purpose for its construction was to supply irrigation water for 
the vast sugar cane producing Mkwasine Estates, other multiple designated uses comprising of domestic water abstraction, lakeshore irrigation, downstream wheat irrigation and small scheme hydroelectric power generation have subsequently evolved (Svubure et al., 2010; ZINWA, 2014). We deliberately established ten non-vegetated littoral sites so as to cover as much as logistically possible the drawdown shoreline zone of the Manjirenji Dam, and chose seven pelagic sites as field controls (Figure 1). We designated each site less than $2 \mathrm{~m}$ deep as a littoral site, with all other sites deeper denoted as pelagic sites and sampled each site once per month from August 2013 to April 2014.

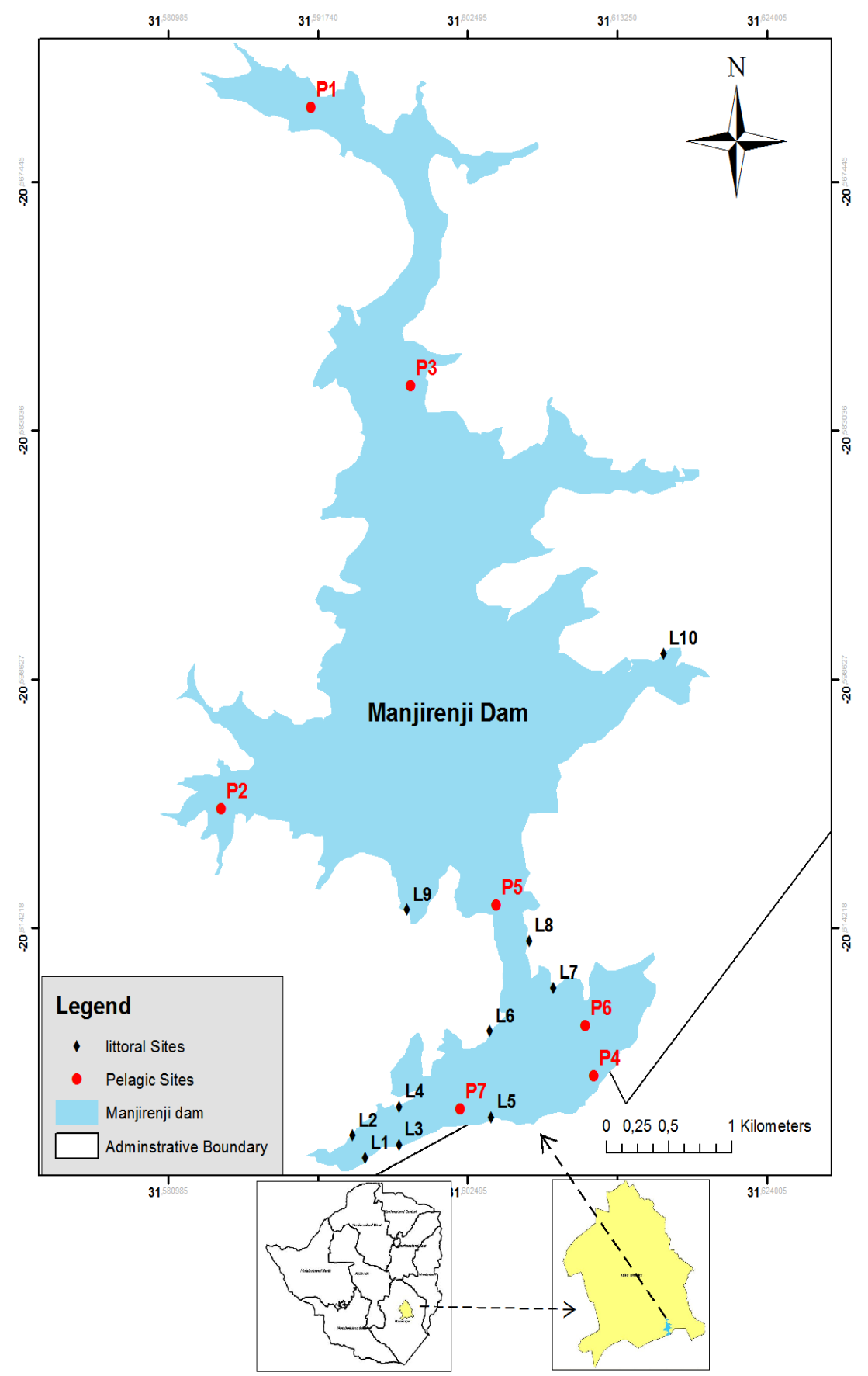

Figure 1. Sampling sites in the Manjirenji Dam. $P=$ Pelagic and $L=$ Littoral. 
Table 1. Morphometry of the Manjirenji Dam source (ZINWA, 2014).

\begin{tabular}{|l|l|}
\hline Name & Manjirenji Dam \\
\hline Location & Chiredzi \\
\hline Construction began & $1964-1967$ \\
\hline Height & 51 metres \\
\hline Length & 382 metres \\
\hline Capacity & $284.2 \mathrm{million}$ cubic metres \\
\hline Catchment area & $1536 \mathrm{~km}^{2}$ \\
\hline Surface Area & $2020 \mathrm{ha}^{2}$ \\
\hline Max water depth & $47 \mathrm{metres}^{2}$ \\
\hline Discharge capacity & $2730 \mathrm{~m}^{3} / \mathrm{s}$ \\
\hline Average depth & $1.35 \mathrm{~m}$ \\
\hline
\end{tabular}

\section{Data collection}

\section{Assessment of physicochemical parameters}

At each site we collected three replicate integrated water samples at a minimum depth of $0.5 \mathrm{~m}$ using a $5 \mathrm{~L}$ Ruttner sampler. All effort was made to take the three replicates at each site and to sample before mid-morning ie $1000 \mathrm{hrs}$ to ensure uniformity. In situ measurements of $\mathrm{pH}$, conductivity, total dissolved solids, temperature, turbidity, dissolved oxygen and Secchi depth were done using a $\mathrm{pH}$ meter, Conductivity meter, Nephelometer, DO meter (HACH, LDO, Germany) and a Secchi disc. Nitrogen, nitrates, ammonia, sulphates total and reactive phosphorus were determined using standards methods from EPA, Hach and Standard Methods in the laboratory (APHA, 1995).

\section{Assessment of phytoplankton and zooplankton}

Phytoplankton were sampled using phytoplankton nets with a diameter of $40 \mathrm{~cm}$ and mesh sizes of $20 \mu \mathrm{m}$, thus excluding picoplankton and nanoplankton. After collection, phytoplankton samples were preserved with Lugol's solution before transfer to the laboratory.

Zooplankton (cladocerans, copepods and large rotifers) were collected with a $12 \mathrm{~L}$ Schindler-Patalassampler (Vanni et al., 1997). Three replicate samples were taken at each site in the pelagic and littoral zone of the lake. The samples from a given site were combined and filtered through a $62 \mu \mathrm{m}$ mesh net, thus excluding picoplankton and nanoplankton, and preserved in 5\% formaldehyde (final concentration). After collection and preservation the phytoplankton and zooplankton samples were transferred to the laboratory for identification and enumeration. Zooplankton were identified and enumerated following the standard Edmondson-Winberg method (1971). Plankton 
species were identified following Needham and Needham (1962). The drop count method (Trivedi and Goel, 1984) was used for the quantitative estimation of the phytoplankton and zooplankton.

\section{Macroinvertebrate sampling}

We used Surber samplers with an area of $0.916 \mathrm{~m}^{2}$ to collect macroinvertebrates from sand and cobble samples in the littoral sites. Woody debris was sampled using forceps to pick organisms off submerged logs for 5 minutes. Surber samplers were used for 5 minute durations at each site. At each site we took a minimum of 5 Surber samples in order to collect a wider variety of macroinvertebrates. Drift net samplers were used to collect macroinvertebrates in the deeper pelagic sites. The drift nets were anchored at each pelagic site for 5 minutes to capture macroinvertebrates. Macroinvertebrate samples were separated from the water, mud and detritus, identified to family level following studies by Gerber and Gabriel (2002), sorted and counted in the field.

\section{Data analysis}

For the purpose of this paper we did not analyse and discuss individual water quality parameters but the detailed water chemistry data are presented in the Appendix section. Spatial and temporal differences in physical chemical parameters were investigated using one way ANOVA at $5 \%$ level of significance using Past 2.16 software (Hammer et al., 2001). Similarly, a Raup Crick cluster analysis to evaluate the similarities and dissimilarities of sites for environmental factors in both the pelagic and littoral zone was done in Past 2.16 (Hammer et al., 2001). We organized the paper along parameters that show great similarity and dissimilarities between sampling sites and exploited the effects of documented water parameters comprising of Secchi depth, total nitrogen (TN), total phosphorus (TP) on chlorophyll $a$ levels. A multiple regression statistical approach was used to elucidate the relationships between Secchi depth TP, TN vs chlorophyll $a$ as a proxy for phytoplankton biomass in the non-vegetated littoral drawdown zone in comparison to the pelagic zone of the turbid shallow dam, Manjirenji in Zimbabwe.

The density of zooplankton and phytoplankton was calculated using the formula by as stated below:

$$
\text { Density }=\text { Number of Organisms }(\text { Org) } / \text { Litres }(\mathrm{L})
$$

The densities calculated were then used to compute the diversity indices. Zooplankton and phytoplankton diversities were calculated using Past 2.16 (Hammer et al., 2001). Shannon Wiener index, evenness, and dominance indices were used for the study as a measure of plankton diversity. Species richness was measured as the total number of zooplankton and phytoplankton species in a particular zone and the detailed results are shown in the Appendix section. The relationship between phytoplankton and zooplankton diversity and environmental factors was investigated using the Canonical Correlation Analysis following the study of Sharma and Sharma (2012), with the CANOCCO 5 software by Ter Braak and Smilauer (2012). 


\section{Results}

\section{Physicochemical parameters}

The full set of water quality parameters is shown in the Appendix section. The $\mathrm{pH}$ values were slightly neutral with the highest value recorded at site $\mathrm{L7}$ of $8.08 \pm 0.85$ (Appendix A). Highest mean water temperature of $30.47 \pm 12.80{ }^{\circ} \mathrm{C}$ were recorded at L3, and DO values averaging $4.2 \mathrm{mgL}^{-1}$ were recorded across sites in both the pelagic and littoral zones (Appendix $A$ and $C$ ). Electrical conductivity values averaging above $79 \mu \mathrm{S} \cdot \mathrm{cm}^{-1}$ were recorded across all littoral and pelagic sites (Appendix $A$ and $C$ ). Turbidity was highest at L4 averaging $221.07 \pm 160.63$ NTU, and high suspended solid (SS) values of $166 \pm 118.58$ and $140.33 \pm 74.14 \mathrm{mgL}^{-}$ ${ }^{1}$ were recorded at sites L4 and L9 respectively (Appendix $C$ ). Relatively higher mean total phosphorus concentrations of $0.47 \pm 0.74$ and $0.31 \pm 0.25 \mathrm{mg} \mathrm{L}^{-1}$ were recorded at L6 and P6 respectively (Appendix $A$ and $C$ ). Comparatively consistent mean ammonia and nitrate values of $0.03 \mathrm{mgL}^{-1}$ were recorded across all littoral and pelagic sites (Appendix $B$ and $D$ ). Mean water transparency was highest in

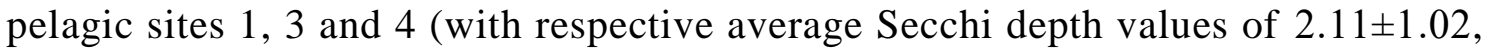
$2.03 \pm 1.11$ and $2.66 \pm 1.23 \mathrm{~m}$ - see Appendix $C$ ). Whilst a high mean sulphate value of $153.93 \pm 155.68 \mathrm{mg} . \mathrm{L}^{-1}$ was recorded at $\mathrm{P} 1$ (Appendix D). High mean chlorophyll $a$ values of $3.45 \pm 1.56,3.57 \pm 0.99,3.32 \pm 1.01 \mu \mathrm{g} \mathrm{L}^{-1}$ were recorded at L5, L9 and $\mathrm{P} 3$ respectively.

There were no significant differences (Anova, $\mathrm{p}>0.05$ ) of $\mathrm{pH}$ at different sites in the littoral zone. There were significant differences of $\mathrm{pH}$ in the pelagic zone, for example site P6 in the pelagic zone differed significantly from sites P2 and P5. Whilst, we detected no significant differences of DO concentrations in the pelagic sites sampled, DO concentration in some sites in the littoral zones such as L2, L4 and L9 differed significantly from sites L8 and L6. We detected no significant variations of TDS values at all the littoral and pelagic sites. However, there were significant differences in the levels of suspended solids (SS) recorded between sites in both the littoral and pelagic zones. For instance in the pelagic zone, the levels of suspended solids at site P6 differed from SS values at P2, P4 and P7. The mean Secchi depth was relatively consistent among littoral sites and did not differ significantly (Anova, $\mathrm{p}>0.05$ ) in the littoral sites of the Manjirenji Dam. However, the mean Secchi depth differed significantly among pelagic sites in the Manjirenji Dam.

We recorded significant variations in total phosphate concentrations among sites in the littoral zone. There were no significant variations in nitrate concentrations among sampling sites in the pelagic zone, though we recorded significant variations in nitrate concentrations among littoral sites. Significant variations in TN concentration were recorded among sites in the pelagic zone, and between site L6 and sites L8 and L9 in the littoral zone of the Manjirenji Dam. Though we recorded no significant differences in EC values among sites in the pelagic zone, the EC values at some littoral sites differed significantly. For instance EC values at site L8 differed significantly from L2 and L6, whilst EC values at sites L1 and L4 differed significantly from site L9 and L10 respectively. We recorded no significant differences in ammonia concentrations across all pelagic and littoral sites. There were significant variations in turbidity among littoral sites, for instance turbidity values at site L7 differed significantly from those recorded at L1 and L3. Chlorophyll $a$ concentrations did not differ significantly ( $p>0.05)$ among 
littoral sites. The Raup Crick cluster analysis computation of site similarity (Figure 2) shows no clear distinction of physical/ chemical parameters between pelagic and littoral sites in the Manjirenji Dam as evidenced in the extensive intersite dichotomy above the 0.95 similarity level characterised by numerous branching off of sites.

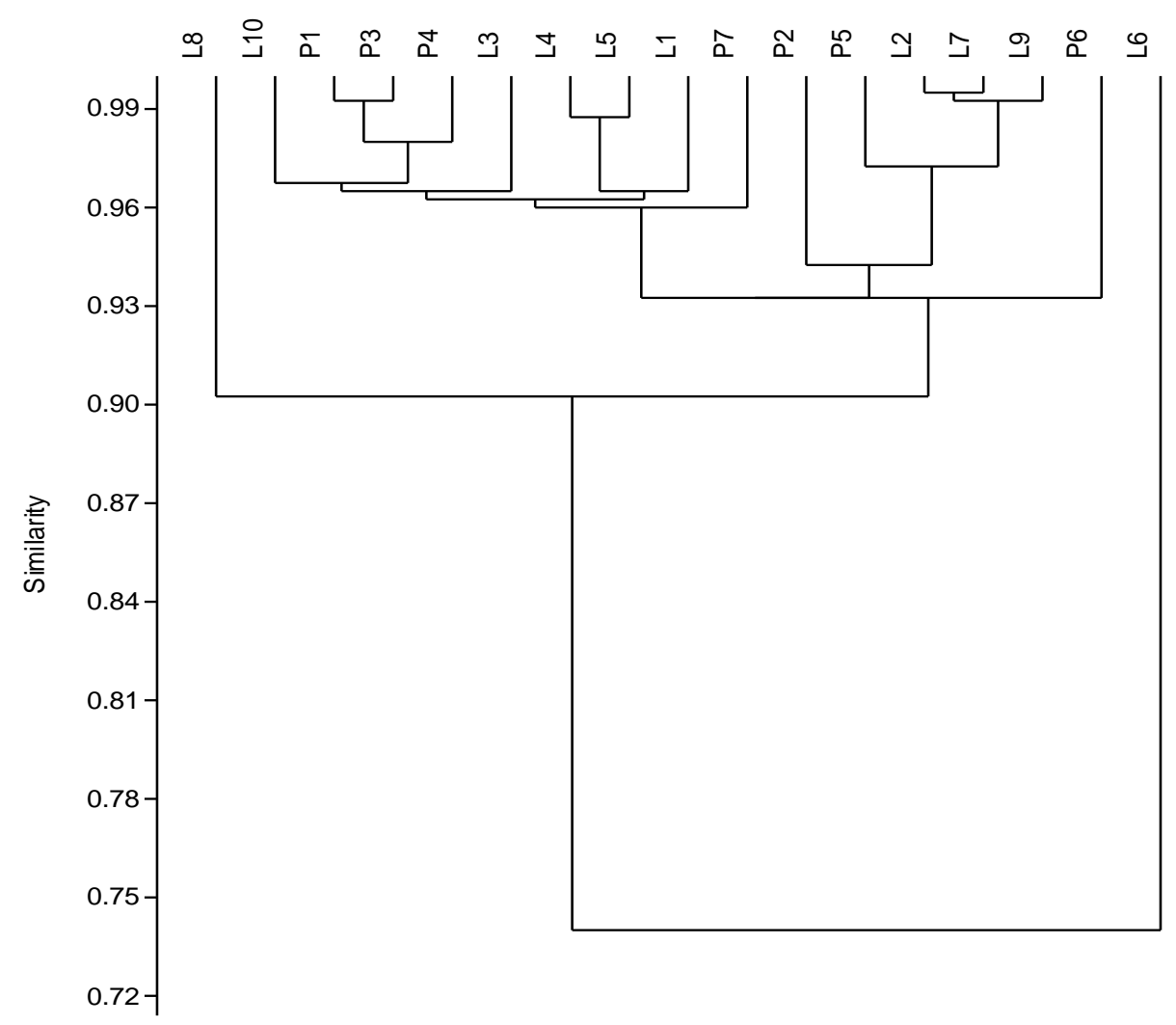

Figure 2. Raup Crick cluster diagram showing site similarities / dissimilarities among pelagic $(P)$ and littoral $(L)$ sites sampled in the Manjirenji Dam.

\section{Phytoplankton community}

Phytoplankton community in Manjirenji Dam comprised of diatoms, chlorophytes, cyanophytes, desmids and euglenophytes. Unknown filamentous algae were grouped in an unspecified group termed 'other groups' in this study. Diatoms consisted of 9 taxa with 10 species. The order of dominance for phytoplankton in the littoral zone comprised of diatoms $(73.5 \%)>$ cyanophyta $(10.1 \%)>$ chlorophyta $(8.8 \%)$. Euglenophytes $(3.8 \%)$, desmids $(2 \%)$ and the other group (1.8\%) were present in smaller quantities. The pelagic zone was also dominated by diatoms $(57 \%)$ followed by euglenophyta (23.4\%) and chlorophyta (17.2\%). Cyanophytes $(1.8 \%)$, desmids $(0.1 \%)$ and the other group $(0.5 \%)$ were present in lower quantities. Five taxa of diatoms were recorded in both the pelagic and littoral zone and they also recurred in all the sampling months. These were Tetraedon regulare, Diatoma, Synedra, Fragillaria and Cymbella. The scatter diagram for phytoplankton dominance reflects overall dominance for diatoms, cyanophyta and desmids in the littoral zone of the Manjirenji Dam (Figure 3). 


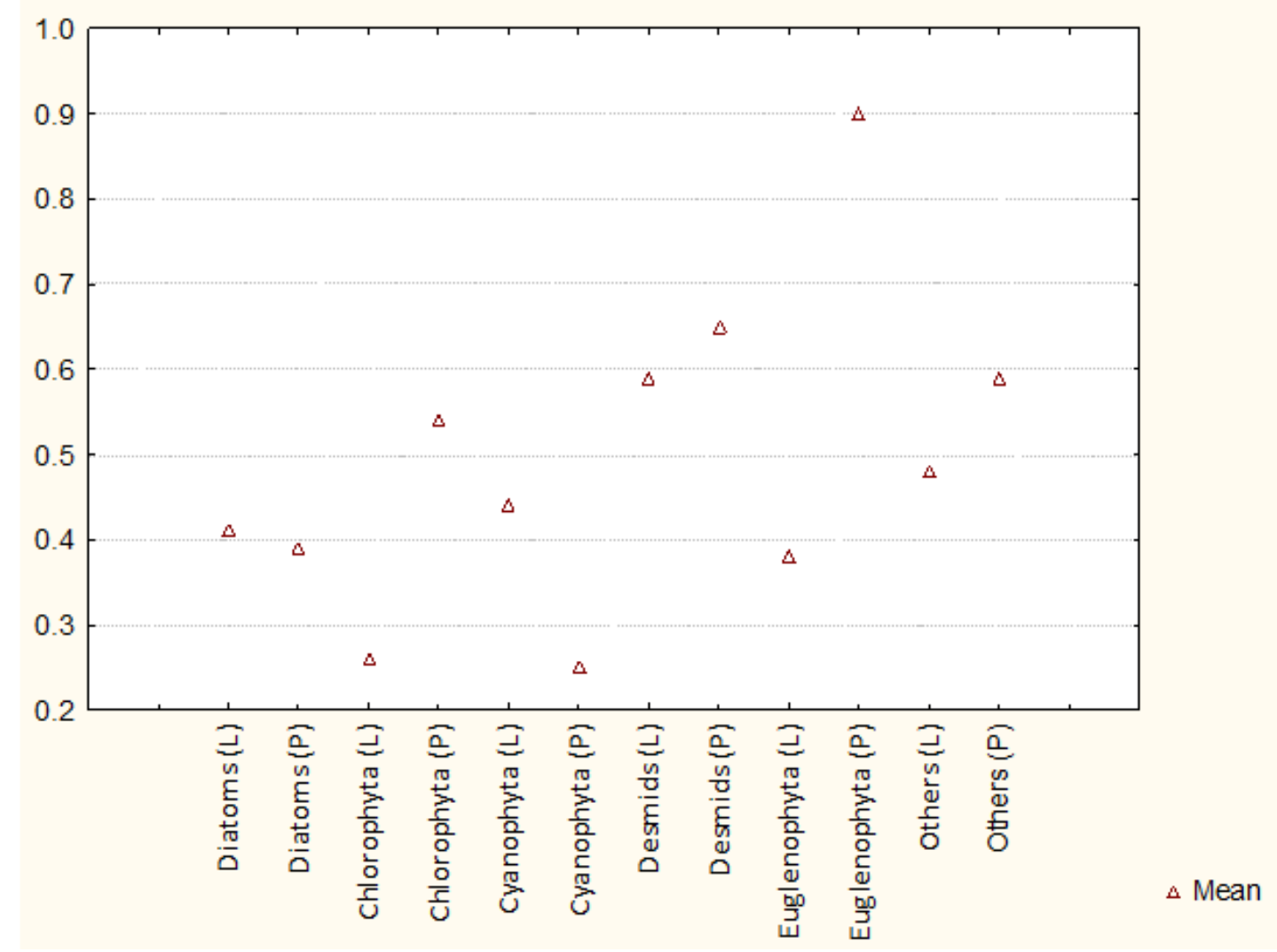

Figure 3. Phytoplankton taxon dominance in pelagic $(P)$ and littoral $(L)$ sites sampled in the Manjirenji Dam.

Diatoma were evenly distributed in both the littoral and pelagic zones and were characterised by low dominance. Although diatoma had high diversity index values, they were surpassed by chlorophyta which was the most diverse group in the littoral zone with a Shannon index of $1.58 \pm 0.3$ (Appendix E). Cyanophytes were the most diverse group in the pelagic zone with a Shannon index of $1.58 \pm 0.18$ (Appendix E). Cyanophytes had a low dominance and higher evenness in both the littoral and pelagic zones (Appendix E). They were more diverse in the pelagic zone than in the littoral zone. Chlorophytes were more diverse in the littoral zone than in the pelagic zone, and were more evenly distributed in the littoral zone than in the pelagic zone and had low dominance in the littoral zone than in the pelagic zone (Appendix E).

We used chlorophyll $a$ as a proxy for phytoplankton biomass in the Manjirenji Dam following Carlson (1977). There were no significant correlations ( $p>0.05$; Spearman test) among the Secchi depth, TN, TP and chlorophyll $a$ for littoral sites. However, chlorophyll $a$ was significantly correlated to $\mathrm{TN}$ in the pelagic zone. High R values (.> 0.60 ) in the pelagic zone indicate a strong relationship among the Secchi depth, TN, TP and chlorophyll $a$ in the pelagic zone (Table 2). Multiple regression indicates no significant predictor factor $(\mathrm{p}<0.05)$ among Secchi depth, TN, TP towards chlorophyll $a$ production in both littoral and pelagic zones in Manjirenji Dam as illustrated by derived equations 1 and 2 . 
Regression equation 1 for chlorophyll a in the littoral zone:

Chlo a $(\mu \mathrm{g} / \mathrm{g})=0.20$ Secchi depth $(\mathrm{m})+0.16 \mathrm{TN}(\mu \mathrm{g} / \mathrm{g})+0.48 \mathrm{TP}(\mu \mathrm{g} / \mathrm{g})-5.072$

$\mathrm{R} 2=0.32, \mathrm{P}$ value $=0.16$

Regression equation 2 for chlorophyll a in the pelagic zone:

Chlo a $(\mu \mathrm{g} / \mathrm{g})=0.16$ Secchi depth $(\mathrm{m})+0.85$ TN $((\mu \mathrm{g} / \mathrm{g})+0.309 \mathrm{TP}(\mu \mathrm{g} / \mathrm{g})-3.807$ $\mathrm{R} 2=0.60, \mathrm{P}$ value $=0.29$

\section{Zooplankton community}

We recorded 3 groups of zooplankton comprising of rotifers, cladocera and copepods in both the littoral and pelagic zones of the Manjirenji Dam. Rotifers consisted of 8 taxa with 14 species, whilst copepods consisted of 6 taxa. Rotifers consisted of Filinia pejleri, Branchionus havaensis, Branchionus calyciflorus, Trichocerca similis, Keratella tropica, Polyartha vulgaris, Keratella quadrata, Tetracerca tropis, Trichocerca elongata, Lecane luna, an unidentified Trichocerca species and Euchlaris dilatata. The Trichocerca similis made up the bulk of rotifers in both the littoral and pelagic zone. Copepods consisted of Afrocyclops, Eudiaptomus, Megacyclops, Macrocyclops, Metaboeckella and nauplii. Cladocerans were composed of 4 taxa namely Daphnia species, Ceriodaphnia, Sididae and Chyrodidae. The scatter diagram for zooplankton dominance show rotifer dominance in the littoral zone, whilst copepods and cladocera dominate in the pelagic sites (Figure 4).

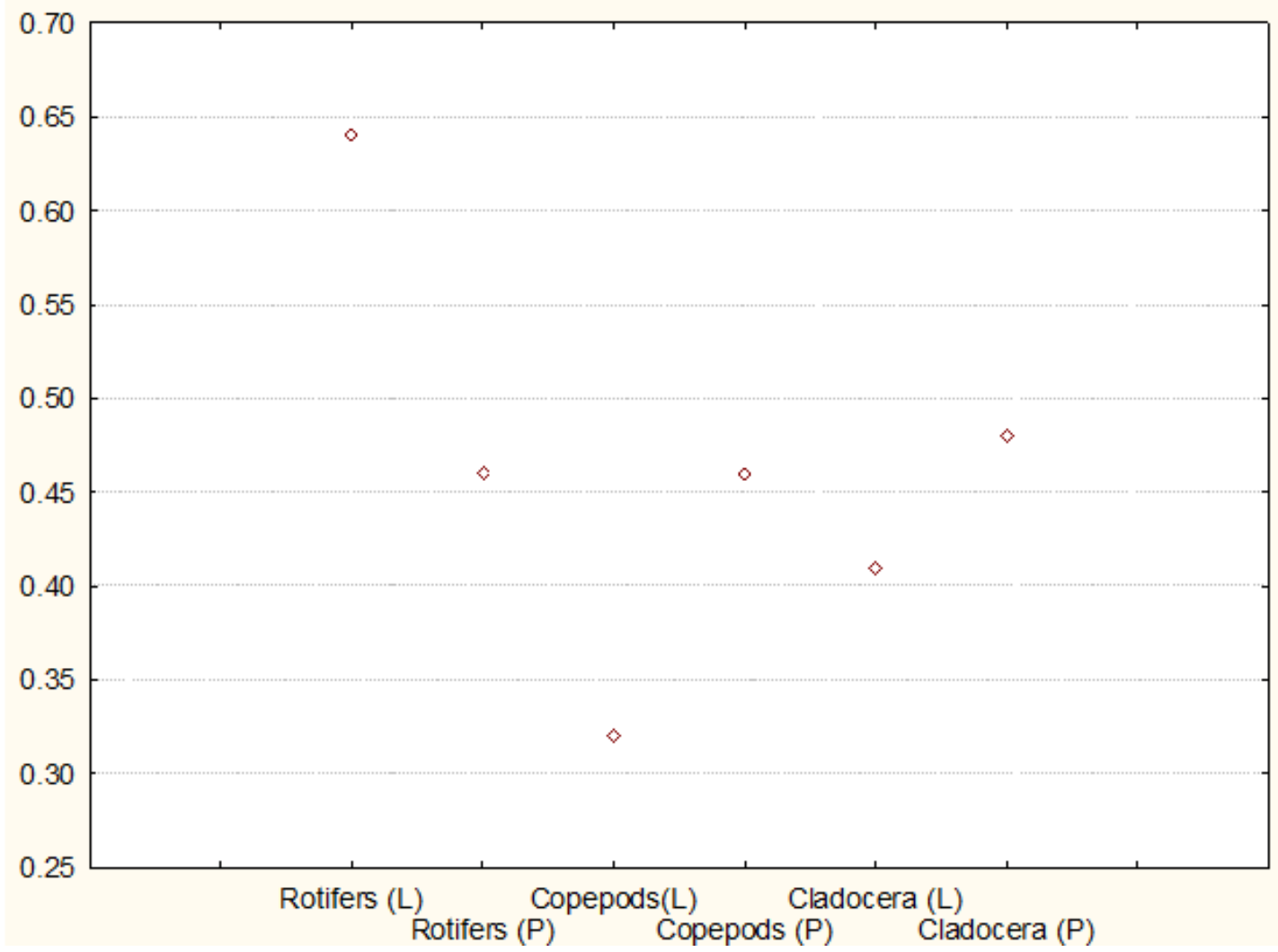

Figure 4. Zooplankton taxon dominance in sites sampled in the Manjirenji Dam 
Table 2. Spearman rank correlation among chlorophyll a, Secchi depth, total nitrogen and total phosphorus in littoral $(L)$ and pelagic $(P)$ sites sampled in the Manjirenji Dam.

Significant relations are denoted *.

\begin{tabular}{lllll}
\hline Pair of variables & Spearman R $(\mathbf{L})$ & P level $(\mathbf{L})$ & Spearman R $(\mathbf{P})$ & P level $(\mathbf{P})$ \\
\hline Chlo $a$ \& Sec depth & 0.19 & 0.60 & 0.75 & 0.052 \\
Chlo $a$ \& TN & 0.22 & 0.53 & 0.82 & $0.02^{*}$ \\
Chlo $a$ \& TP & 0.47 & 0.17 & 0.60 & 0.18 \\
\hline
\end{tabular}

Species richness of zooplankton was $14 \pm 2$ (mean \pm standard deviation) and $11 \pm 2$ for the littoral and pelagic zones respectively (Appendix F). The abundance of zooplankton followed a distinct pattern over the sampling period which consisted of Rotifer > Copepod $>$ Cladocera for both littoral and pelagic sites. Although rotifers were dominant in the littoral and pelagic zones numerically, their diversity in the littoral zone was the lowest among the three groups. Rotifers were however, the most diverse group in the pelagic zone (Appendix F). Copepods and cladocerans were more diverse in the littoral zone than in the pelagic zone. The cladocerans however, were more dominant and also more evenly distributed in the pelagic zone than copepods and rotifers (Appendix F). Rotifers were characterised by higher dominance and lower evenness in the littoral zone and exhibited opposite traits in the pelagic zone. Whilst copepods had low dominance in the littoral zone but were evenly distributed in both the littoral and pelagic zone (Appendix F).

Canonical Correspondence Analysis (CCA) reflect that physicochemical variables accounted for up to $50.37 \%$ of the variation in phytoplankton and zooplankton abundance and distribution in the Manjirenji Dam (Figure 5). Temperature, turbidity and nitrate concentrations positively influenced abundance and distribution rotifers and chlorophytes particularly in the littoral sites (Figure 5). Electrical conductivity, total dissolved solids and dissolved oxygen levels positively influenced the abundance and distribution of diatoms and cladocera in the pelagic sites and at littoral sites near the dam wall. Copepods and euglenophytes were positively influenced by sulphur concentrations in the pelagic sites (Figure 5). However, there was no environmental variable positively associated with zooplankton and phytoplankton at some littoral and pelagic sites like L1. L2. L4, L7, L8, L10, P3 and P4 (Figure 5).

\section{Macroinvertebrate community}

A total of 242 macroinvertebrates belonging to 25 families were recorded in the 10 littoral shorelines sites of the Manjirenji Dam. We recorded a very low number (7) of macroinvertebrates in the pelagic sites to be useful for inclusion in this research. The most dominant taxa with dominance index $>0.50$ were the Notoneumoridae, Belostomatidae, Hydropsychidae, Hydrophilidae, Sphaeridae, and Pyralidae. Physicochemical variables explained $59.59 \%$ of the variation in macroinvertebrates at the ten littoral sites sampled. Total dissolved solids, dissolved oxygen concentrations, electrical conductivity were positively associated with the occurrence and abundance of the Dytiscidae, Elmidae and Helodidae. Nitrate and total phosphorus concentrations positively influenced the distribution of the Hydrophilidae, Physidae, Belostomatidae, Ancylidae, Pyralidae, Lubellidae, Cordullidae, and Sphaeridae. Ammonia concentrations in the littoral zone positively influenced abundance of pollution tolerant macroinvertebrate families such as Chironomidae, Corixidae, Aeshnidae, and Hydrophilidae (Figure 6). Turbidity, total nitrate concentration, suspended solids, and 
the water $\mathrm{pH}$ levels influenced the diversity, abundance and distribution of the pollution sensitive macroinvertebrate taxa that include the Gomphidae, Pisaulidae, Hydropsychidae and Tetragnathidae.

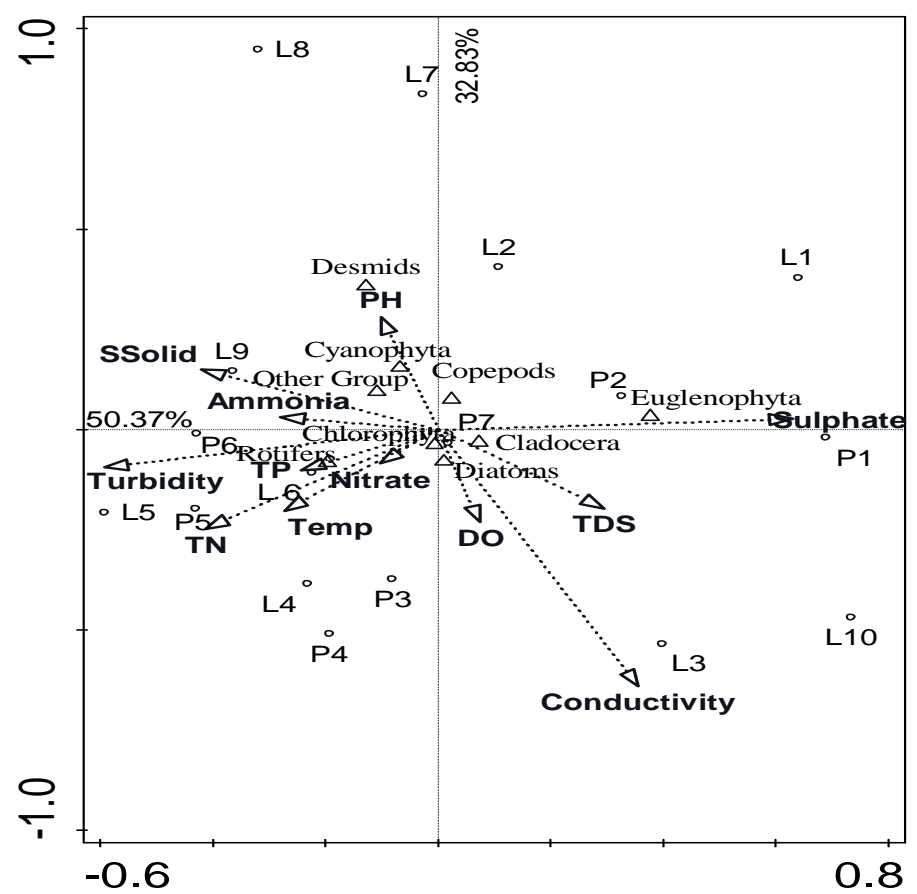

Figure 5. CCA triplot showing the relationship between environmental variables and plankton in the pelagic and littoral zones of the Manjirenji Dam.

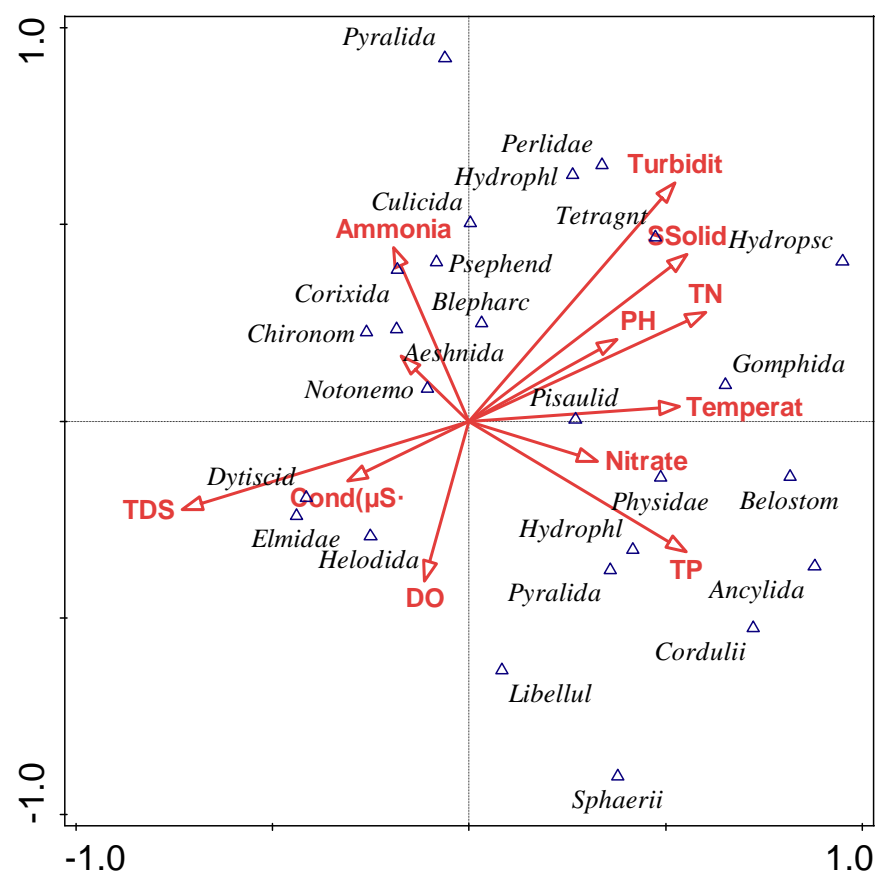

Figure 6. CCA triplot showing associations between physical chemical variables and macroinvertebrates in littoral sites of the Manjirenji Dam. 


\section{Discussion}

The main objectives of this paper were to determine the influence of physicochemical variables on phytoplankton, zooplankton and macroinvertebrate community composition in a shallow dam, Manjirenji in Zimbabwe. And to explore the relations between selected water parameters on chlorophyll $a$ production as a proxy for phytoplankton biomass in the non-vegetated littoral drawdown zone in comparison to the pelagic zone. Our hypothesis was that: shallow lakes with non-vegetated shorelines, show no demarcation or dissimilarity for plankton and macroinvertebrate community composition, and physicochemical variables between the open deeper pelagic and shallow littoral sites.

\section{Physicochemical parameters}

Despite subtle differences in physicochemical parameters in both lake zones, the Raup Crick cluster analysis computation of site similarity shows no clear distinction for most physical/ chemical parameters between pelagic and littoral sites as evidenced in the extensive inter-site dichotomy above the 0.95 similarity level characterised by numerous branching off of sites. This reflects insignificant loss or gain of nutrients in the pelagic system, an observation attributable to intense sediment - water contact, which ensures a rapid reflux and resuspension of most sedimentated nutrients into the open pelagic system (Sheffer, 1998). Moreso, the non-significant spatial differences in water quality parameters indicate the high connectivity between different zones in shallow lentic systems facilitating longitudinal, vertical and lateral exchanges of water and materials (Scheffer and van Nes, 2007). Distinct dissimilarities among littoral sites for nutrients such as nitrates, phosphorus and sulphates reflect intrinsic site specific hydrochemical, hydraulic, and morphometric variations (Dierberg, 1992). As well nonvegetation of both the pelagic and littoral zone, cannot be discounted as a key latent factor driving lateral and vertical nutrient dispersion in this shallow lake, as submerged and emergent macrophytes tend to play crucial roles in either absorbing or releasing nutrients, and through indirect control of redox conditions in aquatic systems (Wetzel, 2001). Thus for a non-vegetated shallow lake, a host of interacting abiotic and biotic factors may impact nutrient stochasticity.

\section{Phytoplankton community composition and chlorophyll a production}

Significant spatial heterogeneity of phytoplankton community in the Manjirenji Dam, reflect an integral site specific uniqueness, spatial isolation, and its concomitant influence on consequent dominant biota (Nowlin et al., 2013; Berggren et al., 2014; Kolzau et al., 2014).

Since physicochemical variables explain $50.37 \%$ of plankton abundance and ecogeography in the dam, it suggests the limited influence of nutrient stochasticity on plankton community composition (George et al., 2012). Moreso it indicates a gap in this study which excluded vital site specific factors such as light intensity, tidal flushing, grazing pressure (Phlips et al., 2002), drawdown landscape disturbance, sedimentation rates and lake level fluctuations (Wang et al., 2011), which can influence plankton communities in shallow water habitats. We do not exclude the impact of water level fluctuations on algal biomass in shallow lakes, although we did not utilise information on them due to lack of supporting water extraction data and hydrological water flow regime for the dam during the study period. For instance, morphometrically, the 
discharge capacity for this shallow dam is $2730 \mathrm{~m}^{3} / \mathrm{s}$ (ZINWA, 2014). This means that about 83 per cent of the whole water volume of the dam could be released per day as $2730 \times 3600 \mathrm{~s} \times 24 \mathrm{~h}=234 \times 10 * * 6 \mathrm{~m}^{3}=83 \%$ of $285 \times 10^{* *} 6 \mathrm{~m}^{3}$. Therefore, the theoretical implications, are that water abstraction and extraction dynamics, affect the water level fluctuations in this shallow dam. How the water level fluctuations affect nutrient stoichiometry and aquatic biodiversity needs further exploration. Suggestions of bathymetrical measurements to determine thermal stratification and infer its influence on phytoplankton community composition, though, prudent, were hampered by the high operating cost, inefficiency, and inapplicability to shallow waters (Zhang et al., 2012).

Regional differences in the relative importance of light and nutrient availability strongly influence spatial and temporal patterns observed in the abundance and composition of phytoplankton in several shallow water bodies (Phlips et al., 1995a; Philps et al., 1997; Sheffer, 1998). Contrastingly, our study observed no significant spatial heterogeneous correlation between water transparency and chlorophyll $a$ concentration. We envisage that the non-vegetation of the littoral drawdown zone and the lack of substantial macrophyte cover in the pelagic zone provide no inhibition to light penetration across the Manjirenji Dam. Despite previous studies on this dam showing a clear absence of shoreline macrophytes, with a muddy drawdown zone devoid of vegetation and an open deep pelagic zone (Utete and Tsamba, 2016), the extended drawdown zone and the shallow littoral sites, dissuaded us from using light climate in predicting photosynthesis and the distribution and development of phytoplankton. The recorded Secchi depth was very low (similar to the euphotic depth), which increase downward attenuation coefficient, surface reflectance or bottom reflectance (Utete and Tsamba, 2016), thus, limiting the influence of light dynamics on phytoplankton community.

The uniform non-algal turbidity values recorded among sites in both the pelagic and littoral zone, reflect uniformity of distribution of nutrients, and further suggests the crucial role of sediment resuspension on phytoplankton abundance and community composition in shallow tropical lakes (Bachmann et al., 2010). Sedimentation of cells is a major factor in the dynamics of pelagic phytoplankton (chiefly diatoms) because diatoms dominated in pelagic and littoral zone sites of Manjirenji Dam. In their study of Lake Apopka, a shallow lake, Schelske et al. (1995) and Bachmann et al., 2010, noted that the abundance of diatoms was positively correlated to wind because of resuspension of tripton and meroplankton in sediments. This may explain the high frequency of recurrence of diatoms in the shallow Manjirenji Dam, as the non-vegetated littoral zone provides no hindrance to wind mixing across the dam, which can further enhance pelagic diatom abundances through sediment resuspension and desorption. We observed algal blooms at some littoral sites which reflect localised pollution, nutrient upwelling, periodic flushing in drawdown zones and pulse release from sediments processes which are significant determinants of nutrient stoichiometry in the littoral zones in shallow lakes (Dierberg, 1992; Paerl and Huisman, 2008).

Our study show that chlorophyll $a$ is strongly related to total nitrogen concentration in the Manjirenji Dam, though a strong correlation between total nitrogen and chlorophyll- $a$ (bottom-up control) in the pelagic zone shows eutrophication avoidance through controlling N input to the dam (Phlips et al., 1997; Scott and McCarthy, 2010). Though, high Spearman test $\mathrm{R}$ values (.> 0.60) in the pelagic zone suggest a strong relationship among the Secchi depth, TN, TP and chlorophyll $a$ in the pelagic zone, this is inadequate to explain relationships between lake nutrient concentrations and 
chlorophyll $a$ concentration, as reflected by distinct predictive powers of the multiple regression equations we derived. In as much, several studies estimate primary production in lakes integrating chlorophyll $a$ concentrations as a proxy for phytoplankton biomass (standing crop) and trophic state (Carlson, 1977). Needless to say there is extended debate over whether nitrogen $(\mathrm{N})$ or phosphorus $(\mathrm{P})$ is the nutrient that ultimately determines productivity in tropical shallow lakes (Schindler, 1977; Vollenweider and Kerekes, 1980; Reynolds, 1999; Lewis and Wurtsbaugh, 2008; Sterner, 2008; Tendaupenyu, 2012). Although the nature of limiting factors can vary spatially and temporally within individual lakes (Piontkovski et al., 1995), the dissimilarity in nitrogen and phosphorus concentrations we recorded among pelagic and littoral sites in tandem with a lack of a significant predictor variable among Secchi depth, TN, TP towards chlorophyll $a$ production in Manjirenji Dam, reflect the complex interplay of internal mechanisms and influence of external forces on nutrient stoichiometry in lakes (Wetzel, 2001). Rather than a single nutrient determining lake productivity, the limiting nutrient in a lake may vary spatially, trophically and seasonally (Quiros, 2003). Complex multiple regressory and curvilinear relationships among chlorophyll $a$, total phosphorus, total nitrogen and water transparency have been shown for many lake data sets, though there exists a tangential rudimentary understanding of the factors that determine TP-TN and TP-Chl $a$ sigmoid patterns (Kolzau et al., 2014). McCauley et al. (1989) recommends for an elucidation of the underlying biological mechanisms that produce the nonlinear response with TN and TP. Furthermore, Watson et al. (1992) suggested that non-linearity reflects an underlying systematic variation in the biomass of functional algal groups. To obtain an insight into how factors like lake depth, flushing, resuspension, grazing interact with nutrient dynamics in determining algal biomass it is prudent to go the empirical regression approach and in future studies analyse algal growth in a more mechanistic way for shallow lakes such as the Manjirenji.

\section{Zooplankton community composition}

Zooplankton dominance analysis show rotifer dominance in the littoral zone, whilst copepods and cladocera dominate in the pelagic sites. Individual taxon versus nutrient analysis was impossible due to the low number of samples we obtained at some sites. However, canonical correspondence analysis indicate that some zooplankton taxa resonate positively with some environmental variable in particular sections of the lake. As the different spatial zones in the shallow Manjirenji Dam share the same water source, geology and history, and appear to be interconnected (reducing chance effects of dispersal with colonisation), differences in zooplankton community structure can be attributed to local biotic and abiotic interactions. Moreso partial explanation of zooplankton abundance and ecogeography by spatial and environmental variable heterogeneity offers insights into the potential effects of factors (we excluded in this study) such as substrate type, sediment- recolonisation (Nhiwatiwa and Marshall, 2010), feeding apparatus adaptations, fish predation pressure (Soares et al., 2010) and the drawdown zone extent (Zohary and Ostrovsky, 2011) and retraction (Wetzel, 2001), in structuring plankton communities in the shallow littoral zones of the Manjirenji Dam. A more explicit consideration of the biologically active resource pools to heterotrophic and autotrophic elements of both phytoplankton and zooplanktonic systems is integral towards a flexible and mechanistic understanding of aquatic ecosystem response to a range of potential environmental changes (Beaver and Havens, 1996). 


\section{Potential interactions between phytoplankton and zooplankton}

Strong interactive relationships exist between phytoplankton and zooplankton as the main systematic groups of zooplankton including many taxa, feed on phytoplankton. Selective grazing by zooplankton is an important factor affecting the structure of phytoplankton communities (Scheffer and van Nes, 2007). Reciprocally, phytoplankton structure also influences the taxonomic composition and dominance of the zooplankton. For instance grazing by cladocerans creates a selective pressure on the phytoplankton community, causing elimination of organisms that do not exceed a precisely defined size (Jeppesen et al., 2002). Predatory copepods influence phytoplankton composition as they target lager sized phytoplankton, whereas nanoplanktonic algae increase in abundance.

For this study copepods and cladocera dominated in the pelagic sites, explaining the significant spatial variation in phytoplankton dominance, as rotifers which are filter feeders dominate the littoral sites. Hence large sized algal species like diatoms, cyanophyta and chlorophyta were dominant in the littoral zone. However, even smaller sized algal species were present in the littoral zone indicating that algal species which are resistant to grazing and predation are more likely to survive, but also can make filter feeding more difficult (Kozak and Gołdyn, 2004). Because of the constant feeding pressure of zooplankton on phytoplankton, the more resistant algae may become more and more abundant during the growing season. This, in combination with the pressure exerted by fish on large-sized zooplankton, results in the restructuring of the community of zooplankton towards the dominance of small-sized organisms resistant to disturbances and trophic interactions.

The domination of small species in the zooplankton community can be associated with fish predation pressure and by the negative influence of cyanophyta or cyanobacteria morphological complexity (Kozak and Gołdyn, 2004). Cyanobacteria was abundant throughout the study period and when their numbers exceed a threshold value, they exert a negative influence on the feeding, development and abundance of large cladocerans. Also, cyanobacterial filaments make their foraging difficult (they block the closing of the carapace), so these algae can influence the decline of the cladoceran community. Thus for our study we observed high diversities in rotifers and cyanobacteria in the littoral zone, where there is localised pollution. Though largersized cladocerans (mainly Daphnia spp.) were quite abundant in the littoral zone and according to Meijer, 2000, in some conditions, they can contribute to the low level of phytoplankton biomass despite a high trophic state of the water. This suggests competitive (biotic) displacement of rotifers from the pelagic zone, with resource partitioning between copepods and cladocera in the pelagic zone. An important consideration would be to determine the ratio of the large filter-feeders in zooplankton community and their distribution across a shallow lake. Moreso, future studies must explore the effect of predation pressure, competition between zooplankton and the importance of filter-feeders in both the littoral and pelagic zone of this shallow lake.

\section{Macroinvertebrate community}

Pollution sensitive macroinvertebrate families dominated the benthic macroinvertebrate community in littoral sites in the Manjirenji Dam as they mostly favour gravel beds or live under aquatic vegetation (Geber and Gabriel, 2002). They colonise solid submerged gravel substrate (Geber and Gabriel, 2002) which was 
abundant in the drawdown zone of the Manjirenji Dam. The negligible abundance of macroinvertebrates recorded in the pelagic zone, shows that most macroinvertebrates prefer macrophyte cover to avoid predation, solid substratum for anchorage and feeding, and well oxygenated water for respiratory functions (Chakona et al., 2009). Despite some physical factors accounting for the presence of pollution tolerant macroinvertebrate families that include the Chironomidae, Corixidae, Aeshnidae, and Hydrophilidae, the non-association of some benthic macroinvertebrates with some physicochemical variables in the littoral sites reflect that the presence / absence of a taxa can be a natural phenomenon (Chakona et al., 2009).

Low levels of variation explained by physicochemical variables (59.59\%) suggest that other, unmeasured latent environmental and biotic factors affect macroinvertebrate community composition in the Manjirenji Dam. Factors such as substrate composition, porosity, and stability, lake bathymetry, drawdown habitat complexity, sediment recolonisation and trophic interactions are important determinants of the range and competitive abilities of benthic macroinvertebrates (Wetzel and Likens, 2000). It implores for further process based studies to better understand causal mechanisms underlying the observed low influence of physicochemical variables on macroinvertebrate abundance in both the littoral drawdown zone and pelagic sites of this shallow dam.

\section{Conservation implications for shallow water lakes}

High overlap and similarity for plankton, macroinvertebrates and physicochemical variables for shallow lakes indicate a modicum to suggest that non-vegetation or reduction of macrophyte beds in the littoral drawdown zone reduces habitat complexity (i.e., surface area, niche availability) allowing unhindered nutrient reflux, circulation and enhancing connectivity with the pelagic zone. Thus, a significant consideration for shallow lakes such as Manjirenji with marked drawdown zones, is the complexity in site selection owing to repeated water level fluctuations, which rapidly turn previously littoral sites into pelagic sites upon inundation, and vice versa upon withdrawal. This force rubric horizontal differences and similarities in nutrient stoichiometry, phytoplankton and zooplankton composition. We suggest that the shallowness of the lake, and the lack of emergent and submerged macrophytes induce hydrodynamic instability and inflexible nutrient stochasticity across the entire dam, thus conferring similarity upon physicochemical parameters in turn distorting the alternative stable equilibria among zooplankton, phytoplankton and macroinvertebrate communities. Hence the functional and habitat similarities between the pelagic and non-vegetated littoral zones. Understanding the transitional nutrient and water transparency dynamics is key to predicting the consequences of management strategies that alter nutrient stoichiometry and the translative effects on aquatic biota within shallow lake ecosystems.

Acknowledgments. We express gratitude to Tamuka Nhiwatiwa, Lindah Mhlanga, Patrick Mutizamhepo, and Elizabeth Munyoro of the Biological Science's Department at the University of Zimbabwe for all the logistical help as well as Exeverino Chinoitezvi and Victor Muposhi of the Wildlife Ecology and Conservation Department, Chinhoyi University of Technology for the map, and the National Parks Authority staff at Manjirenji Station especially Maureen Bepete for the assistance at all stages of the field and laboratory work. 


\section{REFERENCES}

[1] Abrahams, C. (2008): Climate change and lakeshore conservation: a model and review of management techniques -Hydrobiologia 613:33-43.

[2] Antenucci, J.P., Alexander, R., Romero, J. R., Imberger, J. (2003): Management strategies for a eutrophic water supply reservoir, San Roque, Argentina -Water Science Technology 47:49-155.

[3] APHA/AWW/PCF. (1995): Standard Methods for the Examination of water and waste water. $16^{\text {th }}$ Edition. - Washington. 1041-11965.

[4] Baldwin, D.S., Gigney, H., Wilson, J. S., Watson, G., Boulding, A. N. (2008): Drivers of water quality in a large water storage reservoir during a period of extreme drawdown Water Research 42:4711-4724.

[5] Bachmann, R.W., Hoyer, M.V, Canfield, Jr. D.E. (2000): The potential for wave disturbance in shallow Florida lakes -Lake and Reservoir Management 16: 281-291.

[6] Beaver, J.R., Havens, K.E. (1996): Seasonal and spatial variation in zooplankton community structure and their relation to possible controlling variables in Lake Okeechobee -Freshwater Biology 36: 45-56.

[7] Berggren, M., Ziegler, S. E., St-Gelais, N. F. (2014): Contrasting patterns of allochthony among three major groups of crustacean zooplankton in boreal and temperate lakesEcology 95:1947-1959.

[8] Carlson, R.E. (1977): A trophic state index for lakes- Limnology and Oceanography 22:361-369.

[9] Chakona, A., Phiri, C., Chinamaringa, T., Muller, N. (2009): Changes in biota along a dry-land river in north-western Zimbabwe: declines and improvements in river health related to land use -Aquatic Ecology 43: 1095 - 1106.

[10] Dierberg, F.E. (1992): The littoral zone of Lake Okeechobee as a source of phosphorus after a drawdown -Environmental Management 13:-729-742.

[11] Edmondson, W. T., Winberg, G. C. (1971): A manual on methods for the assessment of secondary productivity in freshwaters. -Oxford, Blackwell Scientific Publications.

[12] Gerber, A., Gabriel, M.J.M. (2002): Aquatic. Invertebrates of South African Rivers. Field Guide. -Institute for Water Quality Studies, Pretoria.

[13] George, B., Kumar, J.I.N., Kumar, R. N. (2012): Study on the influence of hydrochemical parameters on phytoplankton distribution along Tapi estuarine area of Gulf of Khambhati, India - The Egyptian Journal of Aquatic Research Volume 38(3):157-170.

[14] Trivedi, M.K., Goel, P.G. (1984): Chemical and biological methods for pollution studiesEnvironmental Publication, Karad: 247.

[15] Grzybkowska, M., Hejduk, J., Zielin ' SKI, P. (1990): Seasonal dynamics and production of Chironomidae in a large lowland river upstream and downstream from a new reservoir in Central Poland -Archiv fur Hydrobiologie 119:439-455.

[16] Hammer O, David A, Harper T and Ryan P. D. (2001): Paleontological Statistics Software Package for Education and Data Analysis. -Paleontological Museum, University of Oslo, Sars Gate1, 0562 Oslo, Norway.

[17] Jeppesen, E., Søndergaard, M., Søndergaard, M. (2002): Cascading trophic interactions in the littoral zone: an enclosure experiment in shallow Lake Stigsholm, Denmark. -Arch Hydrobiologia 153:533-555.

[18] Kolding, J., van Zwieten, P.A.M. (2012): Relative lake level fluctuations and their influence on productivity and resilience in tropical lakes and reservoirs -Fisheries Research 115-116: 99-109.

[19] Kolzau, S., Wiedner, C., Rücker, J., Köhler, J., Köhler, A., Dolman, A. (2014): Seasonal Patterns of Nitrogen and Phosphorus Limitation in Four German Lakes and the Predictability of Limitation Status from Ambient Nutrient Concentrations -PLoS One.9(4): e96065. 
[20] Kozak, A., Gołdyn, R. (2004): Zooplankton versus phyto- and bacterio plankton in the Maltański Reservoir (Poland) during an extensive biomanipulation experiment -Journal of Plankton Research 26:37-48.

[21] Lewis, W.M., Wurtsbaugh, W.A. (2008): Control of lacustrine phytoplankton by nutrients: erosion of the phosphorus paradigm -International Review of Hydrobiology 93: 446-465. doi:10.1002/iroh.200811065.

[22] McCauley, E., Downing, J.F., Watson. S. (1989): Sigmoid relationships between nutrients and chlorophyll among lakes -Canadian Journal of Fisheries and Aquatic Science. 46:1171-1175.

[23] Meijer, L.L. (2000): Biomanipulation in the Netherlands. 15 years of experience. - The Netherlands: Ministry of Transport, Public Works and Water Management, Institute for Inland Water Management and Waste Water Treatment (RIZA)

[24] Needham, J.G., Needham, R.R. (1962): A Guide to the Study of Freshwater Biology. Holden Day Inc San Francisco.

[25] Nhiwatiwa, T., Marshall, B.E. (2010): Water quality and plankton dynamics in 2 small dams in Zimbabwe -Africa. -Journal of Aquatic Science 32(2):139-151.

[26] Nowlin, W.H., Davies, J.M., Nordin, R.N., Mazumder, A. (2004): Effects of water level fluctuation and short-term climate variation on thermal and stratification regimes of a British Columbia reservoir and lake -Lake Reserves Management 20(2):91-109.

[27] Paerl, H.W., Huisman, J. (2008): Blooms like it hot -Science 320: 57-58.

[28] Phlips E. J., Aldridge, F.J., Crisman. T., Schelske. C. (1995a): Relationship between light availability, chlorophyll a, and tripton in a shallow subtropical lake-Limnologica. Oceanography 40:416-412.

[29] Phlips, E., Cichra, J., Havens, M., Hanlon, K., Badylak, C., Rueter, S., Randall, B., Hansen, M, P. (1997): Relationships between phytoplankton dynamics and the availability of light and nutrients in a shallow sub-tropical lake -Journal of Plankton Research 19 (3):319- 342.

[30] Phlips, E.J., Badylak, S., Grosskopf, T. (2002). Factors affecting the abundance of phytoplankton in a restricted subtropical lagoon, the Indian River Lagoon, Florida, USA Estuarine, Coastal and Shelf Science 55:385-402.

[31] Piontkovsi, S. A., Williams, R., Melnik, T.A. (1995): Spatial heterogeneity, biomass and size structure of plankton of the Indian Ocean: some general trends -Marine ecology progress series 117: 219-227.

[32] Quiros, R. (2003): The relationship between nitrate and ammonia concentrations in the pelagic zone of lakes -Limnetica 22 (1-2): 37-50.

[33] Reynolds, C.S. (1999): Modelling phytoplankton dynamics and its application to lake management -Hydrobiologia 395:123-131.

[34] Sharma, B.K., Sharma, S. (2012): Diversity of zooplankton in a tropical floodplain lake of the Brahmapatra river basin, Assam (North-East India) -Opuscular Zoology, Budapest 43(2):187-195.

[35] Schindler, D.W. (1977): Evolution of phosphorus limitation in lakes -Science 195: 260262.

[36] Scott, J. T., McCarthy, M. J. (2010): Nitrogen fixation may not balance the nitrogen pool in lakes over timescales relevant to eutrophication management -Limnologica Oceanic 55: 1265-1270doi:10.4319/lo.2010.55.3.1265.

[37] Schelske, C. L., Carrick, H. J., Aldridge, F. J. (1995): Can wind- induced resuspension of meroplankton affect phytoplankton dynamics? -Journal of American Benthological Society 14: 616-630.

[38] Scheffer, M., Hosper, S. H., Meijer, M.L., Moss, B. (1993): Alternative equilibria in shallow lakes -Trends in Ecology and Evolution 8: 275-279.

[39] Scheffer, M. (1998): Ecology of shallow lakes. -Chapman \& Hall, London.

[40] Scheffer, M., van Nes, E. H. (2007): Shallow lakes theory revisited: various alternative regimes driven by climate, nutrients, depth and lake size -Hydrobiologia 584: 447-455. 
[41] Soares, M.C.S., M. Lurling., Huscar, V. L.M. (2010): Response of the rotifer Branchionus calyciflorus to two tropical toxic cyanobacteria (Cylindrospermopsis raciborski and Microcystis aeruginosa) in pure and mixed diets with green algae -Journal of plankton research 32(7):999-1008.

[42] Sterner, R.W. (2008): On the phosphorus limitation paradigm for lakes -International Review of Hydrobiology 93: 433-445. doi:10.1002/iroh.200811068.

[43] Svubure, O., Soropa, G., Mandirega, S., Rusere, F., Ndeketeya. A, Moyo, D. (2010): Water conflicts on the Manjirenji-Mkwasine irrigation water supply canal, Masvingo Province, Zimbabwe -Journal of Agricultural Extension and Rural Development 2(10): 219-227.

[44] Tendaupenyu, P. (2012): Nutrient limitation of phytoplankton in five impoundments on the Manyame River, Zimbabwe -Water SA 38 (1): 97-104.

[45] Ter Braak, C.J.F., Šmilauer, P. (2012): CANOCO Reference Manual and CanDraw for Windows User's Guide: Software for community ordination, version 5. -Microcomputer Power, Ithaca, New York.

[46] Utete, B., Tsamba, J. (2016): Assessing the relevance of littoral pedestals to chlorophyll a levels in a shallow lentic freshwater system -Water and Environmental Journal 30(34):278-283.

[47] Vanni, M. J., Layne, C. D., Arnott, S. E. (1997): 'Top-down' trophic interactions in lakes:effects for fish on nutrient dynamics -Ecology 78: 1-20.

[48] Vollenweider, R. A., Kerekes, J. (1980): The loading concept as basis for controlling eutrophication philosophy and preliminary results of the OECD programme on eutrophication -Progress in Water Technology 12: 5-38.

[49] Wang, L., Cai., Q., Xu, Y., Kong, L., Tan, L., Zhang, M. (2011): Weekly dynamics of phytoplankton functional groups under high water level fluctuations in a subtropical reservoir bay -Aquatic Ecology 45(2):197-212.

[50] Wantzen, K.M., Rothhaupt, K.O., Mortl. M., Cantonati, M., Laszlo, G.T., Fischer, P. (2008): Ecological effects of water-level fluctuations in lakes: an urgent issue Hydrobiologia 613:1-4.

[51] Watson, S., McCauley, E., Downing J.A. (1992): Sigmoid relationships between phosphorus, algal biomass, and algal community structure -Canadian Journal of Fisheries and Aquatic Science 49: 2605-2610.

[52] Wetzel, R.G. (2001): Limnology: lake and river ecosystems. -London, Academic Press.

[53] Wetzel, R. G., Likens, G. E. (2000): Limnology. 2nd edition. -Springer-Verlag, New York.

[54] Zimbabwe National Water Authority. (2014): Dams of Zimbabwe. Compendium. Government Publishers.

[55] Zhang, B., Xianfang, S., Yinghua, Z., Dongmei, H., Changyuan, T., Yilei, Y., Ying, M. (2012): Hydrochemical characteristics and water quality assessment of surface water and groundwater in Songnen plain, Northeast China -Water Research 46: 2737-2748.

[56] Zohary, T., Ostrovsky, I. (2011): Ecological impacts of excessive water level fluctuations in stratified freshwater lakes -Inland Waters 1:47-59. 
Appendix A. Water physical variables (mean \pm SD) for littoral zones in the Manjirenji Dam.

\begin{tabular}{ccccccccc}
\hline Site & $\mathrm{pH}$ & $\begin{array}{c}\text { Temperature } \\
\left({ }^{0} \mathrm{C}\right)\end{array}$ & $\begin{array}{c}\mathrm{DO} \\
\left(\mathrm{mg} \cdot \mathrm{L}^{-1}\right)\end{array}$ & $\begin{array}{c}\text { Conductivity } \\
\left(\mu \mathrm{S} \cdot \mathrm{cm}^{-1}\right)\end{array}$ & $\begin{array}{c}\mathrm{TDS} \\
\left(\mathrm{mgL}^{-1}\right)\end{array}$ & $\mathrm{SS}\left(\mathrm{mgL}^{-1}\right)$ & Turbidity (NTU) & $\begin{array}{c}\text { Secchi } \\
\text { depth }(\mathrm{m})\end{array}$ \\
\hline L1 & $7.29 \pm 0.79$ & $26.53 \pm 10.92$ & $4.62 \pm 10.18$ & $79.30 \pm 28.05$ & $57.33 \pm 4.04$ & $84.00 \pm 26.06$ & $114.13 \pm 51.74$ & $1.99 \pm 0.37$ \\
L2 & $7.44 \pm 0.55$ & $28.03 \pm 11.68$ & $4.47 \pm 10.87$ & $78.53 \pm 27.80$ & $54.67 \pm 3.51$ & $90.67 \pm 33.50$ & $119.7 \pm 49.89$ & $1.54 \pm 0.34$ \\
L3 & $7.50 \pm 1.03$ & $30.17 \pm 12.65$ & $4.86 \pm 11.73$ & $80.87 \pm 28.44$ & $53.00 \pm 4.58$ & $77.67 \pm 43.92$ & $110.2 \pm 50.75$ & $1.99 \pm 0.48$ \\
L4 & $7.74 \pm 0.73$ & $29.77 \pm 12.39$ & $4.77 \pm 11.51$ & $82.03 \pm 28.78$ & $54.67 \pm 2.89$ & $166.00 \pm 118.58$ & $221.07 \pm 160.63$ & $1.93 \pm 0.41$ \\
L5 & $7.70 \pm 0.69$ & $30.47 \pm 12.80$ & $4.05 \pm 12.02$ & $80.30 \pm 28.46$ & $54.33 \pm 3.21$ & $84.33 \pm 52.00$ & $162.87 \pm 112.21$ & $1.66 \pm 0.37$ \\
L6 & $7.54 \pm 1.06$ & $29.47 \pm 12.40$ & $4.78 \pm 11.48$ & $77.90 \pm 27.67$ & $54.33 \pm 3.51$ & $67.00 \pm 58.08$ & $102.27 \pm 72.46$ & $1.66 \pm 0.35$ \\
L7 & $8.08 \pm 0.85$ & $28.37 \pm 11.65$ & $4.37 \pm 10.94$ & $77.47 \pm 27.70$ & $53.33 \pm 4.93$ & $84.00 \pm 48.59$ & $112.53 \pm 64.9$ & $1.71 \pm 0.42$ \\
L8 & $7.76 \pm 0.63$ & $27.63 \pm 11.36$ & $4.44 \pm 10.62$ & $78.23 \pm 27.77$ & $51.00 \pm 7.55$ & $117.33 \pm 30.89$ & $123.00 \pm 29.46$ & $1.78 \pm 0.47$ \\
L9 & $7.79 \pm 0.87$ & $28.10 \pm 11.58$ & $5.40 \pm 10.70$ & $79.13 \pm 27.62$ & $52.33 \pm 10.69$ & $140.33 \pm 74.14$ & $181.00 \pm 93.66$ & $1.78 \pm 0.47$ \\
L10 & $7.44 \pm 1.00$ & $27.43 \pm 11.35$ & $5.43 \pm 10.47$ & $82.00 \pm 28.86$ & $57.67 \pm 10.07$ & $57.67 \pm 5.13$ & $72.67 \pm 14.57$ & $1.54 \pm 0.34$ \\
\hline
\end{tabular}


Appendix B. Water nutrients (mean $\pm S D$ ) for littoral zones in the Manjirenji Dam.

\begin{tabular}{lllllll}
\hline Site & $\begin{array}{l}\mathrm{TP} \\
\left(\mathrm{mg} \mathrm{L}^{-1}\right)\end{array}$ & $\begin{array}{l}\mathrm{TN} \\
\left(\mathrm{mg} \mathrm{L}^{-1}\right)\end{array}$ & $\begin{array}{l}\text { Nitrate } \\
\left(\mathrm{mg} . \mathrm{L}^{-1}\right)\end{array}$ & $\begin{array}{l}\text { Ammonia } \\
\left(\mathrm{mg} . \mathrm{L}^{-1}\right)\end{array}$ & $\begin{array}{l}\text { Sulphate } \\
\left(\mathrm{mg} . \mathrm{L}^{-1}\right)\end{array}$ & $\begin{array}{l}\text { Chlorophyll } a \\
\left(\mu \mathrm{g} \mathrm{L}^{-1}\right)\end{array}$ \\
\hline L1 & $0.12 \pm 0.06$ & $0.94 \pm 1.16$ & $0.03 \pm 0.02$ & $0.02 \pm 0.01$ & $73.24 \pm 34.69$ & $1.40 \pm 0.70$ \\
L2 & $0.11 \pm 0.10$ & $1.54 \pm 1.32$ & $0.03 \pm 0.03$ & $0.02 \pm 0.01$ & $56.88 \pm 48.25$ & $1.87 \pm 0.11$ \\
L3 & $0.12 \pm 0.13$ & $1.6 \pm 1.38$ & $0.01 \pm 0.01$ & $0.02 \pm 0$ & $60.36 \pm 15.63$ & $2.31 \pm 1.01$ \\
L4 & $0.28 \pm 0.34$ & $1.53 \pm 1.32$ & $0.03 \pm 0.02$ & $0.02 \pm 0$ & $53.13 \pm 14.47$ & $1.23 \pm 0.34$ \\
L5 & $0.04 \pm 0.03$ & $1.33 \pm 1.06$ & $0.01 \pm 0.00$ & $0.03 \pm 0.02$ & $50.52 \pm 38.35$ & $3.45 \pm 1.56$ \\
L6 & $0.47 \pm 0.74$ & $0.8 \pm 1.22$ & $0.04 \pm 0.02$ & $0.02 \pm 0$ & $53.62 \pm 26.9$ & $0.97 \pm 0.11$ \\
L7 & $0.12 \pm 0.14$ & $0.76 \pm 1.24$ & $0.04 \pm 0.04$ & $0.01 \pm 0$ & $65.23 \pm 25.95$ & $2.48 \pm 0.87$ \\
L8 & $0.06 \pm 0.03$ & $0.77 \pm 0.99$ & $0.02 \pm 0.02$ & $0.02 \pm 0.01$ & $53.19 \pm 18.49$ & $2.21 \pm 0.33$ \\
L9 & $0.28 \pm 0.39$ & $0.81 \pm 1.17$ & $0.03 \pm 0.03$ & $0.02 \pm 0.01$ & $67.66 \pm 23.09$ & $3.57 \pm 0.99$ \\
L10 & $0.04 \pm 0.01$ & $0.57 \pm 0.94$ & $0.01 \pm 0.00$ & $0.02 \pm 0.01$ & $61.66 \pm 23.22$ & $3.01 \pm 0.77$ \\
\hline
\end{tabular}


Appendix C. Water physical variable (mean $\pm S D$ ) for pelagic zones in the Manjirenji Dam.

\begin{tabular}{lllllllll}
\hline Site & $\mathrm{pH}$ & $\begin{array}{l}\text { Temperature } \\
\left({ }^{0} \mathrm{C}\right)\end{array}$ & $\begin{array}{l}\mathrm{DO} \\
\left(\mathrm{mg} . \mathrm{L}^{-1}\right)\end{array}$ & $\begin{array}{l}\text { Conductivity } \\
\left(\mu \mathrm{S} \cdot \mathrm{cm}^{-1}\right)\end{array}$ & $\begin{array}{l}\mathrm{TDS} \\
\left(\mathrm{mgL}^{-1}\right)\end{array}$ & $\begin{array}{l}\mathrm{SS} \\
\left(\mathrm{mgL}^{-1}\right)\end{array}$ & $\begin{array}{l}\text { Turbidity } \\
(\mathrm{NTU})\end{array}$ & $\begin{array}{l}\text { Secchi } \\
\text { Depth }(\mathrm{m})\end{array}$ \\
\hline P1 & $7.95 \pm 0.69$ & $28.17 \pm 11.56$ & $4.32 \pm 10.87$ & $81.70 \pm 28.68$ & $54.00 \pm 3.46$ & $70.67 \pm 42.15$ & $87.90 \pm 34.83$ & $2.11 \pm 1.02$ \\
P2 & $7.83 \pm 0.84$ & $28.60 \pm 11.82$ & $4.40 \pm 11.07$ & $79.87 \pm 28.1$ & $57.33 \pm 15.70$ & $76.33 \pm 66.26$ & $117.37 \pm 73.02$ & $1.97 \pm 0.93$ \\
P3 & $7.92 \pm 0.63$ & $26.00 \pm 10.46$ & $4.27 \pm 9.88$ & $81.03 \pm 28.43$ & $51.33 \pm 7.02$ & $81.67 \pm 70.87$ & $129.63 \pm 86.09$ & $2.03 \pm 1.11$ \\
P4 & $7.43 \pm 1.04$ & $28.30 \pm 11.71$ & $5.08 \pm 10.81$ & $78.63 \pm 27.87$ & $54.67 \pm 3.79$ & $76.33 \pm 62.88$ & $107.23 \pm 65.19$ & $2.66 \pm 1.23$ \\
P5 & $7.80 \pm 1.10$ & $27.90 \pm 11.38$ & $4.64 \pm 10.65$ & $80.13 \pm 28.29$ & $55.33 \pm 11.93$ & $84.33 \pm 66.23$ & $117.97 \pm 83.32$ & $1.89 \pm 1.02$ \\
P6 & $7.82 \pm 0.94$ & $27.80 \pm 11.34$ & $4.18 \pm 10.71$ & $80.10 \pm 28.27$ & $57.00 \pm 7.00$ & $78.00 \pm 64.16$ & $113.83 \pm 74.83$ & $1.71 \pm 0.89$ \\
P7 & $7.50 \pm 0.60$ & $27.603 \pm 11.45$ & $3.98 \pm 10.76$ & $80.73 \pm 28.61$ & $55.33 \pm 7.51$ & $77.00 \pm 59.86$ & $108.97 \pm 72.44$ & $1.78 \pm 0.98$ \\
\hline
\end{tabular}


Appendix D. Water nutrients (mean $\pm S D$ ) for pelagic zones in the Manjirenji Dam.

\begin{tabular}{lllllll}
\hline Site & $\begin{array}{l}\text { TP } \\
\left(\mathrm{mg} \mathrm{L}^{-1}\right)\end{array}$ & $\begin{array}{l}\text { TN } \\
\left(\mathrm{mg} \mathrm{L} \mathrm{L}^{-1}\right)\end{array}$ & $\begin{array}{l}\text { Nitrate } \\
\left(\mathrm{mg} . \mathrm{L}^{-1}\right)\end{array}$ & $\begin{array}{l}\text { Ammonia } \\
\left(\mathrm{mg} . \mathrm{L}^{-1}\right)\end{array}$ & $\begin{array}{l}\text { Sulphate } \\
\left(\mathrm{mg} . \mathrm{L}^{-1}\right)\end{array}$ & $\begin{array}{l}\text { Chlorophyll } a \\
\left(\mu \mathrm{L} \mathrm{L}^{-1}\right)\end{array}$ \\
\hline P1 & $0.11 \pm 0.03$ & $0.70 \pm 1.06$ & $0.03 \pm 0.03$ & $0.02 \pm 0.01$ & $153.93 \pm 155.68$ & $2.10 \pm 0.30$ \\
P2 & $0.06 \pm 0.01$ & $0.77 \pm 1.14$ & $0.04 \pm 0.04$ & $0.01 \pm 0.00$ & $48.89 \pm 37.38$ & $1.70 \pm 0.20$ \\
P3 & $0.15 \pm 0.07$ & $0.76 \pm 1.02$ & $0.04 \pm 0.05$ & $0.01 \pm 0.00$ & $63.36 \pm 39.22$ & $3.32 \pm 1.01$ \\
P4 & $0.12 \pm 0.04$ & $0.78 \pm 1.26$ & $0.05 \pm 0.07$ & $0.01 \pm 0.00$ & $55.20 \pm 19.74$ & $2.03 \pm 0.34$ \\
P5 & $0.06 \pm 0.04$ & $1.63 \pm 1.12$ & $0.04 \pm 0.06$ & $0.02 \pm 0.01$ & $56.63 \pm 46.75$ & $1.27 \pm 0.56$ \\
P6 & $0.31 \pm 0.25$ & $1.62 \pm 1.13$ & $0.05 \pm 0.03$ & $0.02 \pm 0.01$ & $59.91 \pm 44.32$ & $1.56 \pm 0.11$ \\
P7 & $0.04 \pm 0.02$ & $1.61 \pm 1.21$ & $0.03 \pm 0.01$ & $0.02 \pm 0.01$ & $55.02 \pm 32.78$ & $1.21 \pm 0.87$ \\
\hline
\end{tabular}


Appendix E. Phytoplankton diversities in littoral and pelagic zones.

\begin{tabular}{lllllll}
\hline & Dominance & \multicolumn{3}{c}{ Shannon } & \multicolumn{2}{c}{ Evenness } \\
Phytoplankton & $\mathrm{L}$ & $\mathrm{P}$ & $\mathrm{L}$ & $\mathrm{P}$ & $\mathrm{L}$ & $\mathrm{P}$ \\
\hline Diatoms & $0.41 \pm 0.07$ & $0.39 \pm 0.07$ & $1.19 \pm 0.15$ & $1.17 \pm 0.12$ & $0.4 \pm 0.08$ & $0.52 \pm 0.05$ \\
Chlorophyta & $0.26 \pm 0.08$ & $0.54 \pm 0.29$ & $1.58 \pm 0.3$ & $0.87 \pm 0.49$ & $0.64 \pm 0.12$ & $0.45 \pm 0.22$ \\
Cyanophyta & $0.44 \pm 0.22$ & $0.25 \pm 0.05$ & $1.26 \pm 0.46$ & $1.58 \pm 0.18$ & $0.51 \pm 0.3$ & $0.78 \pm 0.12$ \\
Desmids & $0.59 \pm 0.17$ & $0.65 \pm 0.36$ & $0.67 \pm 0.27$ & $0.67 \pm 0.76$ & $0.75 \pm 0.06$ & $0.86 \pm 0.13$ \\
Euglenophyta & $0.38 \pm 0.07$ & $0.9 \pm 0.16$ & $1.12 \pm 0.17$ & $0.18 \pm 0.28$ & $0.75 \pm 0.18$ & $0.60 \pm 0.37$ \\
Other_groups & $0.48 \pm 0.24$ & $0.59 \pm 0.32$ & $1.12 \pm 0.5$ & $0.81 \pm 0.67$ & $0.58 \pm 0.24$ & $0.69 \pm 0.14$ \\
\hline
\end{tabular}

Appendix F. Zooplankton diversities in littoral and pelagic zones.

\begin{tabular}{lllllll}
\hline Zooplankton & Dominance & \multicolumn{3}{c}{ Diversity } & \multicolumn{3}{c}{ Evenness } \\
& $\mathrm{L}$ & $\mathrm{P}$ & $\mathrm{L}$ & $\mathrm{P}$ & $\mathrm{L}$ & $\mathrm{P}$ \\
\hline Rotifers & $0.64 \pm 0.34$ & $0.46 \pm 0.12$ & $0.82 \pm 0.71$ & $1 \pm 0.15$ & $0.36 \pm 0.23$ & $0.56 \pm 0.23$ \\
Copepods & $0.32 \pm 0.07$ & $0.46 \pm 0.03$ & $1.41 \pm 0.18$ & $0.86 \pm 0.07$ & $0.59 \pm 0.1$ & $0.73 \pm 0.13$ \\
Cladocerans & $0.41 \pm 0.22$ & $0.48 \pm 0.17$ & $1.18 \pm 0.49$ & $0.84 \pm 0.38$ & $0.65 \pm 0.05$ & $0.82 \pm 0.2$ \\
\hline
\end{tabular}

